Check for updates

Cite this: RSC Adv., 2017, 7, 37175

\title{
Xylitol based phase selective organogelators for potential oil spillage recovery $\dagger$
}

\author{
Chinthalapati Siva Kesava Raju, (D) * Bhaskar Pramanik, Raman Ravishankar, \\ Peddy Venkat Chalapathi Rao and Gandham Sriganesh
}

Received 20th June 2017

Accepted 20th July 2017

DOI: $10.1039 / \mathrm{c} 7 \mathrm{ra06898k}$

rsc.li/rsc-advances

\begin{abstract}
Xylitol based phase selective organogelators are developed for crude oil of varying API gravity and various petroleum fractions/oils. Intermolecular hydrogen bonding was responsible for gel formation with three dimensional cross linked networks. Efficient gelation at room temperature, high mechanical strength, oil recovery and gelator reusability make these compounds promising candidates for oil spill mitigation.
\end{abstract}

Water pollution has become a serious problem for mankind in the 21st century. ${ }^{1}$ There are a number of ways by which water is being polluted in which oil spillage, a result of accidental or intentional release of petroleum products in the environment, is one route. ${ }^{2,3}$ The world has witnessed several oil spillage incidents and one of the major incidents in recent time is the 5 billion barrels of crude oil release in the Gulf of Mexico. ${ }^{4}$ The adverse effects of oil spillage are observed on marine ecosystems and the economy associated with spilled oil mitigation. ${ }^{5}$ Conventional methods for oil spill recovery include combustion, mechanical treatment using oil sorbent materials, chemical treatment by dispersants, and bioremediation with microorganisms. ${ }^{6}$ All of these processes are associated with certain drawbacks like poor recovery, release of toxic residues, being uneconomical, time consuming etc. Recently low molecule organogelators (LMWGs) have gained immense interest as an alternate to mitigate oil spills..$^{7-9}$

LMWGs having molecular weight $<2000 \mathrm{Da}$ can translate to three dimensional fibrillar networks in presence of suitable solvent via intermolecular self-assembly. ${ }^{10,11}$ The nono-scale or micro-scale network structure are formed by non-covalent interactions like hydrogen bonding, $\pi-\pi$ stacking, van der Walls interactions, dipole-dipole interactions, charge transfer interactions. ${ }^{12}$ Apart from internal forces external conditions like heating-cooling cycle, solvent change, sonication, analyte addition, pH change, light and oxidation/reduction etc. govern gel formation. ${ }^{13,14}$ Gels are solid-like network in liquid-like medium which can display the rheological properties of solidphase materials, high surface area for liquid phase and rapid internal diffusion kinetics for self healing. ${ }^{15}$ These distinct properties of gel dictates vast range of applications in catalysis,

Analytical Division, Hindustan Petroleum Green R\&D Center (HPGRDC), KIADB Industrial Estate, Tarabahalli, HoskoteTaluk, Bangalore, 560067, Karnataka, India. E-mail: cskraj@hpcl.in

$\dagger$ Electronic supplementary information (ESI) available: Synthetic procedure, gelation video. See DOI: 10.1039/c7ra06898k pharmaceuticals, bio-technology, light harvesting, lubricants and food industry. ${ }^{16-19}$ LMWGs that can selectively solidify oils from oil-water biphasic mixture at room temperature (phaseselective gelators, PSGs) have become popular and demanding as ideal solidifying material for oil spill recovery. ${ }^{7,8}$ Since the first report of PSG by Bhattacharya and co-workers with alaninebased amphiphile ${ }^{20}$ there are several reports regarding phase selective gelator molecules. The ideal PSGs for oil spill recovery must fulfil some requirements such as: (a) cost effective and easily synthesizable (b) selective and efficient gelation of oil phase, (c) rapid gelation at room temperature, (d) stable gel with respect to temperature and external force, (e) easy oil recovery from the gel phase, and (f) reusable.

Aiming for various applications, a wide range of molecular building blocks like peptides, sugars, paraffinic alcohols, nucleo-bases, acids, steroids, ureas are used for LMWG synthesis and gel formation. ${ }^{12,20-40}$ Sugar based gelators are one of the important class from economic perspective, ease of synthesis and biocompatibility. ${ }^{27-46} \mathrm{John}$ and co-workers in 2010 demonstrated a model study with reduced sugar (mannitol) based amphiphile PSGs for oil spill treatment. ${ }^{29}$ Following the pathway of selective protection of hydrophilic - $\mathrm{OH}$ groups in sugars by hydrophobic groups, several authors have reported mannitol, ${ }^{29-33}$ sorbitol, ${ }^{34-37}$ glucose, ${ }^{38-40}$ galactose ${ }^{41,42}$ arabinose $^{43,44}$ and other sugar based PSGs. ${ }^{45,46}$ But, xylitol based phase selective gelator is not reported so far. In general, synthesis of sugar based PSGs follow protection of the hydroxyl groups by hydrophobic groups and based on the degree of protection the final compound may be oil selective or water selective. The distinct feature of these kind of sugar based gelators is that carbohydrate part is capable of forming hydrogen bonding to allow various self assembled structures and hydrophobic groups promote the building blocks by $\pi-\pi$ stacking and van der Waals interactions. ${ }^{27,45,46}$ Sugar based gelators, reported so far are effective for phase selective gelation of solvents and various oils such as petrol, diesel, kerosene, etc. in presence of water. However, the major oil-spills caused by 
crude-oil, mainly during transportation through sea or during drilling which is associated with more rigorous challenge for recovery, are mitigated by sugar based gelators; are reported by very few authors. ${ }^{33,39,43,44}$ As already discussed earlier that heating-cooling process is tedious and not viable over sea. Room temperature gelation is preferred choice for these type of typical applications. Recent literatures indicate the mitigation of crude oil spills by sugar based gelators, applying them in solution phase or as powder at room temperature. ${ }^{33,39,43,44}$ Regardless of some recent progress in the field, there is still a significant need to develop many more examples of cost effective, less toxic and easily applicable LMWGs to handle the real situation of a marine oil spill.

Inspired by the progress of research work in the area of sugar-derived LMWGs, ${ }^{27,28}$ sugar based compounds having hydroxyl groups to support hydrogen bonding, aromatic part and alkyl chain to favor oil phase gelation are developed in this present work. In this paper, xylitol based organogelators have been reported capable of gelating a series of organic solvents, mineral oils, crude oils and edible oils. Phase selective oil phase gelation from oil-water mixture at room temperature followed by recovery of both oil and gelator are also presented (Scheme 1).

The gelator compounds were synthesized in a single step by acid catalyzed reaction between xylitol and aromatic aldehyde/ ketone in a biphasic system comprise of methanol and cyclohexane. Enhanced solubility of the product in cyclohexane than methanol favour the reaction going forward and white solid products were obtained in 64 to $90 \%$ yields.

Gelation ability of three xylitol based compounds in different solvents and oils are tested and the results are represented in Table 1. The table infer that all these compounds have poor gelation abilities towards paraffinic solvents, whereas they are quite efficient for aromatic solvents. Minimum uptake capabilities of 1-3 towards aromatic solvents vary in between 70 to 95 times and that for paraffinic solvents it's in between 50 to 60 times. Superior efficiency of 1-3 for aromatic solvents than that for paraffinic solvents might be due to the presence of aromatic hydrophobic part in these gelator compounds coming from two protecting aromatic groups. They all are unable to convert low molecular weight paraffinic solvents $e . g$. hexane and octane to obtain their respective gel however, heavier paraffinic solvents i.e. hexadecane and dodecane can be converted to gel. Thus, higher the molecular weight of the paraffinic solvent lower is the MGC. The same trend is followed for aromatic solvents too. Another observation can be made from the table that gelation ability of these compounds toward aromatic as well as paraffinic solvents decreases from 1 to 3 . This phenomenon can be attributed to the increasing hydrophobicity in the alkyl side chain from compound 1 to 3 .

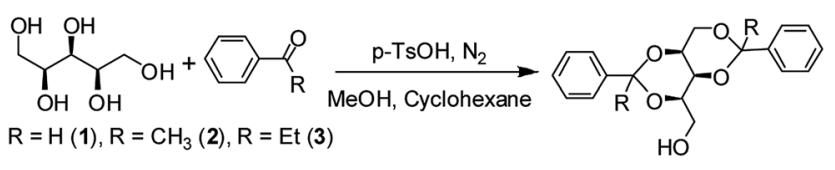

Scheme 1 Synthetic scheme of the gelator compounds 1-3.
Table 1 Gelation abilities of compounds 1-3 in different hydrocarbon solvents ${ }^{a}$

\begin{tabular}{|c|c|c|c|c|c|c|}
\hline \multirow[b]{2}{*}{$\begin{array}{l}\text { Solvent } \\
\text { system }\end{array}$} & \multicolumn{2}{|l|}{1} & \multicolumn{2}{|l|}{2} & \multicolumn{2}{|l|}{3} \\
\hline & $\begin{array}{l}\text { MGC } \\
(\% \mathrm{w} / \mathrm{v})\end{array}$ & MUC & $\begin{array}{l}\text { MGC } \\
(\% \mathrm{w} / \mathrm{v})\end{array}$ & MUC & $\begin{array}{l}\text { MGC } \\
(\% \mathrm{w} / \mathrm{v})\end{array}$ & MUC \\
\hline Hexane & $\mathrm{P}$ & $\mathrm{P}$ & $\mathrm{P}$ & - & $\mathrm{P}$ & - \\
\hline Octane & $\mathrm{P}$ & $\mathrm{P}$ & $\mathrm{P}$ & - & $\mathrm{P}$ & - \\
\hline Dodecane & 1.8 & 55 & 1.91 & 52 & $\mathrm{P}$ & - \\
\hline Hexadecane & 1.65 & 60 & 1.75 & 57 & 1.9 & 52 \\
\hline Benzene & 1.16 & 86 & 1.22 & 81 & 1.43 & 69 \\
\hline Toluene & 1.12 & 89 & 1.2 & 83 & 1.37 & 72 \\
\hline Xylene & 1.05 & 95 & 1.2 & 83 & 1.35 & 74 \\
\hline CRN & 1.07 & 93 & 1.28 & 78 & $\mathrm{P}$ & - \\
\hline SRN & 1.31 & 76 & $\mathrm{P}$ & - & $\mathrm{P}$ & - \\
\hline Kero & 0.62 & 161 & 1.1 & 90 & 1.84 & 54 \\
\hline Diesel & 0.43 & 232 & 0.62 & 161 & 0.77 & 129 \\
\hline Crude oil & 1.69 & 59 & 1.85 & 54 & 2.01 & 49 \\
\hline Vegetable oil & 0.65 & 153 & 0.78 & 128 & 0.92 & 108 \\
\hline
\end{tabular}

${ }^{a}$ MGC $=$ Minimum Gelation Concentration (amount in $\mathrm{g}$ of gelator required for $100 \mathrm{ml}$ of hydrophobic material to be gelated), MUC = Minimum Uptake Capability (volume in $\mathrm{ml}$ of hydrophobic material gelated by $1 \mathrm{~g}$ of gelator), $\mathrm{P}=$ Precipitate.

After performing the gelation experiment of the compounds for different solvents they were subjected for different oils, especially refinery distillates as well as crude oil and vegetable oil. The results are provided in the Table 1 . All three gelators were capable in transforming different oils into gel phase with different MGC values ranging from 0.43 to $2 \% \mathrm{w} / \mathrm{v}$. Crude oil with complex composition had least gelation tendency than its different fractions. Minimum uptake capability for crude oil was found to be in between 49 to 59 times whereas the maximum gelation ability was observed for diesel (upto 232 times). Poor gelation ability of the compounds with paraffinic solvents is reflected in their gelation ability with refinery distillates too. Straight Run Naphtha (SRN) having least aromatic content than other distillates had the lowest gelation efficiency than others; even gelator $\mathbf{2}$ and $\mathbf{3}$ was unable to form gel with SRN. Cracked Naphtha (CRN) having higher percentage of unsaturates e.g. olefins and aromatics was gelated easily than SRN. Moving from lighter fractions to heavier fractions (i.e. SRN to Diesel via Kero cut) aromatic content gradually increases resulting successive increment of gelation ability. Thus combination of molecular weight factor and aromatic content factor leads to the observation that heavier oil fraction is easily gelated than the lighter one. Comparison of gelation ability of 1-3 for crude oil as well for other oils dictates superior gelation ability of $\mathbf{1}$ followed by $\mathbf{2}$ and $\mathbf{3}$. Apart from petroleum oils, vegetable oil was also converted to gel, exhibiting minimum uptake capabilities ranging from 108 to 153 times.

Among the different oils that are studied for gelation, crude oil was chosen as model for oil spill recovery experiment. Crude oil being a complex mixture of thousands of hydrocarbons as well as metal impurities is always challenging for gelation studies. Again based on the nature of hydrocarbons present in crude oil its property varies drastically for different crude oils. 


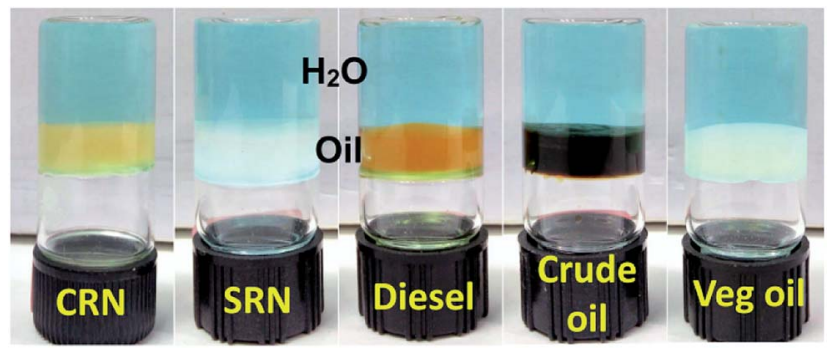

Fig. 1 Photographs of gels with different oils in a biphasic mixture with water ( $\mathrm{CuSO}_{4}$ solution results blue colour of the aqueous phase).

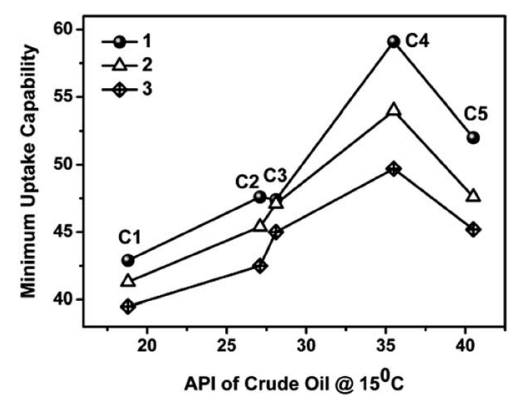

Fig. 2 Gelation by 1-3 with different crude oils-water biphasic mixture denoted by $C 1$ to $C 5$ (C1: API 18.8, C2: API 27.1; C3: API 28.1, C4: API 35.5; and C5: API 40.5).

The effect of the composition of crude oil on the gelation ability of 1-3 were performed with different crudes of varying API gravities ranging from very low API $\left(\mathrm{C} 1,18.8^{\circ}\right)$ to high API (C5, $40.5^{\circ}$ ). Fig. 2 demonstrate the effect of crude oil API density over the gelation property of xylitol based gelators. Minimum uptake capabilities ranging from 40 to 60 times for various crude oils are quite remarkable regarding their compositional complexities. The heavy crude (lower API) exhibited higher MGC and lighter crude (higher API) exhibited lower MGC and the uptake capability decreased with increase in API gravity. Thereby a reduction in the uptake capacity with lowering API may be attributed to the successive increment of resins \& asphaltene content in crude oil. The lightest crude of our study (API 40.5) didn't follow the same trend and gelation ability found to be inferior to that of adjacent lighter crude. This observation may be due to the higher paraffinic content in the extra light crude (C5) reflecting the poor gelation capability of 1-3 for paraffinic solvents. This infers that more than API the constituents present in the crude will dictate the gelation. These experiments infer that xylitol sugars are effective as gelators for different crudes covering the wide spectrum of crude basket available from different parts of the globe.

As the prime focus was on oil spillage recovery, the gelators are required to be effective for selective oil phase gelation without gelating the aqueous phase from oil-water biphasic mixture. Six oil samples containing crude oil, refinery distillates as well as vegetable oil were subjected for phase selective gelation. Experimental results are given in Table 2 and represented in Fig. 1. All three gelators were able to gelate exclusively the oil phase without altering the water phase during performance evaluation gelation experiments. Gelation abilities of the gelators followed the same order as reported in Table 1 i.e. gelation ability trend is $\mathbf{1}>\mathbf{2}>\mathbf{3}$. Selective gelation revealed that MGCs for all oils were increased very slightly from their respective individual/single phase studies might be due to partial solubility of the gelators in aqueous phase as observed earlier. ${ }^{31}$ Considering the practical application of oil spill recovery, effect of water salinity over gelation ability was crosschecked by using sea water in the biphasic mixture. The data from Table 2 inform the similarity of gelation abilities i.e. similar MGC \& MUC values in sea water to that of normal water. Thus, ability of the organogelators towards gelation for oil phase is highly encouraging even under extreme conditions revealing practical application towards oil spillage recovery over sea.

There are a number of processes that can be applied for phase selective gelation of oil phase. Those most commonly used processes are (a) dissolution of the phase selective gelator in oil by heating and cooling to form gel ${ }^{42}$ (b) dissolution of the gelator in soluble solvents e.g. alcohols, ethers at room

Table 2 Gelation abilities of compound $1-3$ in various biphasic mixtures ${ }^{a}$

\begin{tabular}{|c|c|c|c|c|c|c|}
\hline \multirow[b]{2}{*}{ Solvent system } & \multicolumn{2}{|l|}{1} & \multicolumn{2}{|l|}{2} & \multicolumn{2}{|l|}{3} \\
\hline & MGC (\% w/v) & MUC & MGC (\% w/v) & MUC & MGC (\% w/v) & MUC \\
\hline CRN-water & 1.2 & 83.3 & 1.31 & 76.3 & $\mathrm{P}$ & - \\
\hline SRN-water & 1.4 & 71.4 & $\mathrm{P}$ & - & $\mathrm{P}$ & - \\
\hline Kero-water & 0.65 & 153.8 & 1.17 & 85.4 & 1.85 & 54.0 \\
\hline Diesel-water & 0.5 & 200 & 0.73 & 136.9 & 0.8 & 125 \\
\hline Crude-water & 1.8 & 55.5 & 1.96 & 51.0 & 2.05 & 48.7 \\
\hline Veg oil-water & 0.7 & 142.8 & 0.81 & 123.4 & 0.98 & 102.0 \\
\hline CRN-sea water & 1.2 & 83.3 & 1.35 & 74.07 & $\mathrm{P}$ & - \\
\hline SRN-sea water & 1.38 & 72.4 & $\mathrm{P}$ & - & $\mathrm{P}$ & - \\
\hline Kero-sea water & 0.65 & 153.8 & 1.2 & 83.3 & 1.85 & 54.0 \\
\hline Diesel-sea water & 0.48 & 208.3 & 0.75 & 133.3 & 0.82 & 121.9 \\
\hline Crude-sea water & 1.81 & 55.2 & 1.95 & 51.2 & 2.1 & 47.6 \\
\hline Veg oil-sea water & 0.7 & 142.8 & 0.8 & 125 & 1.0 & 100 \\
\hline
\end{tabular}

${ }^{a}$ MGC $=$ Minimum Gelation Concentration, MUC $=$ Minimum Uptake Capability, $\mathrm{P}=$ Precipitate. 


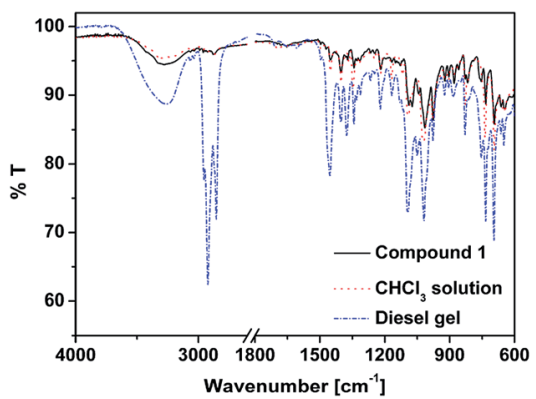

Fig. 3 FT-IR spectra of gelator 1, in chloroform and xerogel obtained from diesel.

temperature and adding the solution over oil, ${ }^{29,32,38}(\mathrm{c})$ dissolution of the gelator in the same liquid that to be gelated or in a suitable water immiscible solvent by heating having solution concentration much higher than MGC to spray over biphasic mixture under hot condition, ${ }^{25,26,31,33,43,44}$ (d) applying xerogels i.e. dried gels. ${ }^{39}$ Some limitations are associated with these processes like heating-cooling cycle for process-A is practically impossible on the sea level, water miscible solvents for process$\mathrm{B}$ are environmental hazard for marine lives, uneconomical heating and use of more amount of gelator to congeal oil along with the carrier solvent is associated with process-C whereas poor efficiency of xerogels limits their application for process-D. Such limitations can easily be removed using the gelator in solid state at room temperature without using any solvent and/ or heating as reported by Sureshan et al. ${ }^{39}$ Application of compounds 1-3 in solid state as powder didn't exhibit any gelation process which drove us to find an alternate way of application. Room temperature phase selective gelation was experimented by dissolving the gelators in oil immiscible solvent toluene. In a typical procedure $10 \%$ solution of the gelator was prepared by dissolving it in toluene and the mixture is heated gently to make it as solution. To a $25 \mathrm{ml}$ of crude oil layer over $100 \mathrm{ml}$ of sea water the gelator solution was applied to ensure complete dispersion. Within a 2 minutes the crude oil layer is transformed to the gel state. Thus, utilizing the toluene, phase selective gelation of crude oil as well as other oil fractions are possible. ${ }^{26}$ Gelation time observed for refinery fractions like naphtha, kerosene and diesel are found to be less than 1 minute. However, vegetable oil and crude oil gelation have taken more than 2 minutes for proper gelation because of the complexity.

In order to exhibit the application of these gelators in oil spill recovery, a model oil spill set-up by adding SRN to sea water

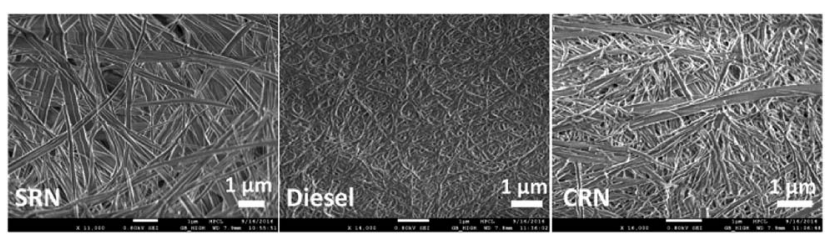

Fig. 4 SEM images of xerogels by 1 obtained from SRN, diesel and CRN. taken in a glass tray was made and DCM solution was added to it. As shown by ESI video, $\dagger$ SRN layer was transformed in gel that was collected from the water surface by scooping for further recovery of oil. The effectiveness of gelator towards the recovery of oil from gel phase was performed showing $97 \%$ oil recovery. The gel can be reused for more than 5 times with recovery up to $90 \%$ with refinery fractions. Similar experiment with crude oil exhibited oil recovery of $53 \%$ upto boiling point of $350{ }^{\circ} \mathrm{C}$. As crude oil is complex and final boiling point can be more than $700^{\circ} \mathrm{C}$, recovery of gel from crude oil is difficult process. Also gel contains mainly hydrocarbons with oxygenated compounds, hence oil gel can go as feed with Fluidised Catalytic Cracking (FCC) unit.

FT-IR spectroscopy gave the information about non-covalent interactions involved in gelation process (Fig. 3). As discussed earlier that hydrogen bonding interaction plays an important role, which can be observed from FT-IR study. ${ }^{15}$ The FT-IR spectra of 1 in non-gelating solvent chloroform didn't change from its solid state i.e. the broad peak at $3294 \mathrm{~cm}^{-1}$ for $-\mathrm{OH}$ group remained unchanged signifying no hydrogen-bonded aggregation in a non-gelating solvent. However in the diesel gel of 1 , the peak at $3294 \mathrm{~cm}^{-1}$ shifted to $3250 \mathrm{~cm}^{-1}$ with increased intensity, which confirms the presence of intermolecular hydrogen bonding network involved in gel formation..$^{30}$

The morphology study of the supramolecular organogels was carried out by scanning electron microscopy (SEM) and Fig. 4 represents the SEM images in various oils by compound $\mathbf{1}$. The SEM images from various petroleum fractions revealed the formation of self-assembled fibrillar networks and different textures were obtained from different oils. Three dimensional fibrous networks in diesel are denser than that of the others. The fiber length was several micrometers having cross linking dimension of few nanometers. The SEM image of xerogel from CRN-gel and SRN-gel also confirmed the presence of fibrous bundled network with increasing fiber chain length and width. The presence of hydrogen bonding is believed to be the driving force for such three dimensional cross-linked fiber assembly which was proved earlier also from FT-IR study. Thus -OH group present in each molecule, by involving in intermolecular hydrogen bonding leads to self-assembled fibrillar networks where entrapped solvent molecules may result as the supramolecular gel.

Stability and strength of the gels were studied as practical application of the gelators for oil recovery requires structural
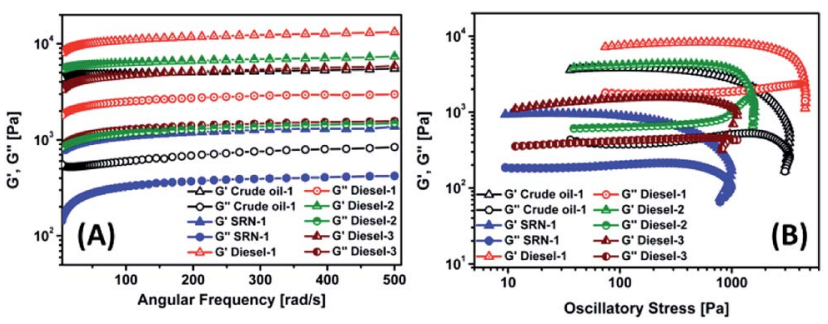

Fig. 5 Dynamic rheology of the organogels obtained from different oils: (A) as a function of angular frequency and (B) as a function of oscillatory stress at $25^{\circ} \mathrm{C}$. 
integrity of the gels under harsh condition for a longer period of time. Stability of the gels was found to be very high, floating over the aqueous layer for several weeks without deteriorating the gels.

Mechanical strength of the organogels was studied by rheology experiments in oscillatory mode. Both frequency sweep and amplitude sweep experiments were performed to deduce two main parameters namely storage modulus $\left(G^{\prime}\right)$ and loss modulus $\left(G^{\prime \prime}\right)$. The elastic modulus $G^{\prime}$ in frequency sweep experiment of the gels as shown in Fig. 5, is much higher than the viscous modulus $G^{\prime \prime}$ where both parameters are independent of frequency in the frequency range of 5-500 $\mathrm{rad} \mathrm{s}^{-1}$. This observation is typical for the viscoelastic gel behaviour as the gel state is signified by $G^{\prime}>G^{\prime \prime}$ and in the sol state is signified by $G^{\prime}<$ $G^{\prime \prime}$; where $G^{\prime}$ corresponds to the ability of the deformed material to store energy and $G^{\prime \prime}$ signifies the flow behaviour of the material under stress. ${ }^{29,39,44}$ The storage modulus value in the order of $10^{3}-10^{4} \mathrm{~Pa}$ indicates strong gel state to be retained when a small strain was imposed. The highest storage modulus was observed for diesel gel by $\mathbf{1}$; can be correlated to the lower MGC and better cross-linking by SEM image. Crude oil gel by 1 had better mechanical strength than SRN gel as expected from MGC values in Table 1. Oscillatory sweep experiments were also carried out to indentify gel-sol transition point. Applying a significant shear strain to the gel and its arranged structure can be destroyed; identified by the crossover point of $G^{\prime}$ and $G^{\prime \prime}$ (Fig. 5) and $G^{\prime \prime}>G^{\prime}$ condition is in accordance with the sol-like flowing state. ${ }^{33}$ Fig. 5 revealed the gelation ability trend of $\mathbf{1}>\mathbf{2}>$ 3 with respect to the mechanical strength of their diesel gels and the crossover point of $G^{\prime}$ and $G^{\prime \prime}$.

In conclusion, $\mathrm{C}_{5}$-reduced sugar based xylitol was utilized to synthesis small molecule organogelators 1-3 by selectively protecting the hydroxyl groups with carbonyl compounds. The synthesized amphiphilic compounds exhibited phase selective gelation of hydrophobic solvents or oils in presence of aqueous phase. Aromatic solvents were easily transformed into gel, using the gelators having aromatic protecting group in their structure, than the paraffinic solvents; again heavier paraffinic hydrocarbons were easy to form gel than the lighter hydrocarbons. Effectiveness of the gelators was not only limited to common solvents but also observed for a large number of refinery distillates along with crude oil. Complexity of crude oil limited the gelation efficiency around 50 times whereas heavier mineral oils exhibited much higher gelation efficiency (i.e. $\mathrm{MUC}=232$ for diesel by $\mathbf{1}$ ) than the lighter oils (i.e. MUC $=76$ for SRN by $\mathbf{1}$ ). Successful demonstration of the gelation process for various crude oils with varying densities covering almost the entire crude basket, inferred the applicability of 1-3 for the mitigating/ containing the oil spillage. Recovery of oil from gel phase was also demonstrated to emphasize on applicability of the gelators. Mechanical strength of the gels; an important parameter to collect gels over aqueous layer for oil recovery, was remarkable as a consequence from three dimensional network. FT-IR and SEM studies concluded the presence of strong intermolecular hydrogen bonding for self-assembled fibrillar network being the prime factor for the gel formation. Compounds 1-3 differ in the alkyl chain $[\mathrm{R}=-\mathrm{H}(\mathbf{1}),-\mathrm{Me}(2)$ and $-\mathrm{Et}(\mathbf{3})]$ associated with the protecting carbonyl compound where hydrophobicity increases from compound 1 to 3 . Increasing hydrophobicity had inverse effect on their gelation ability. Gelation result for specific oil by 1-3 as well as mechanical strength revealed the gelation efficiency to follow the order $\mathbf{1}>\mathbf{2}>3$.

\section{Notes and references}

$1 \mathrm{WHO}$ /UNICEF, Investing in water and sanitation: Increasing access, reducing inequalities, World Health Organization, Geneva, 2014.

2 M. Fingas, Handbook of Oil Spill Science and Technology, Wiley, US, 2015.

3 L. Guterman, Science, 2009, 323, 1558.

4 On Scene Coordinator Report on Deepwater Horizon Oil Spill, 2011, http://www.uscg.mil/foia/docs/dwh/ fosc_dwh_report.pdf.

5 Y. Gong, X. Zhao, Z. Cai, S. E. O'Reilly, X. Hao and D. Zhao, Mar. Pollut. Bull., 2014, 79, 16.

6 D. Dave and A. E. Ghaly, Am. J. Environ. Sci., 2011, 7, 423.

7 B. O. Okesola and D. K. Smith, Chem. Soc. Rev., 2016, 45, 4226.

8 K. Liu, P. He and Y. Fang, Sci. China: Chem., 2011, 54, 575.

9 Y. Ohsedo, Polym. Adv. Technol., 2016, 27, 704.

10 Molecular Gels: Materials with Self-Assembled Fibrillar Networks, ed. R. G. Weiss and P. Terech, Springer, Dordrecht, Netherlands, 2006.

11 P. Terech and R. G. Weiss, Chem. Rev., 1997, 97, 3133.

12 J.-L. Li and X.-Y. Liu, Adv. Funct. Mater., 2010, 20, 3196.

13 M. D. Segarra-Maset, V. J. Nebot, J. F. Miravet and B. Escuder, Chem. Soc. Rev., 2013, 42, 7086.

14 P. Dastidar, Chem. Soc. Rev., 2008, 37, 2699.

15 S. Yu, L. Chen, M. Zhang and T. Yi, Chem. Soc. Rev., 2014, 43, 5346.

16 N. M. Sangeetha and U. Maitra, Chem. Soc. Rev., 2005, 34, 821.

17 S. Banerjee, R. K. Das and U. Maitra, J. Mater. Chem., 2009, 19, 6649.

18 A. R. Hirst, B. Escuder, J. F. Miravet and D. K. Smith, Angew. Chem., Int. Ed., 2008, 47, 8002.

19 K. J. Skilling, F. Citossi, T. D. Bradshaw, M. Ashford, B. Kellam and M. Marlow, Soft Matter, 2014, 10, 237.

20 S. Bhattacharya and Y. Krishnan-Ghosh, Chem. Commun., 2001, 0, 185.

21 C. Tomasini and N. Castellucci, Chem. Soc. Rev., 2013, 42, 156.

22 S. Debnath, A. Shome, S. Dutta and P. K. Das, Chem.-Eur. J., 2008, 14, 6870.

23 (a) S. Basak, J. Nanda and A. Banerjee, J. Mater. Chem., 2012, 22, 11658; (b) D. K. Maiti and A. Banerjee, Chem.-Asian J., 2013, 8, 113; (c) A. K. Das, P. P. Bose, M. G. B. Drew and A. Banerjee, Tetrahedron, 2007, 63, 7432.

24 T. Kar, S. Debnath, D. Das, A. Shome and P. K. Das, Langmuir, 2009, 25, 8639.

25 C. Ren, G. H. B. Ng, H. Wu, K.-H. Chan, J. Shen, C. Teh, J. Y. Ying and H. Zeng, Chem. Mater., 2016, 28, 4001. 
26 C. S. K. Raju, B. Pramanik, T. Kar, P. V. C. Rao, N. V. Choudary and R. Ravishankar, RSC Adv., 2016, 6, 53415.

27 S. Datta and S. Bhattacharya, Chem. Soc. Rev., 2015, 44, 5596.

28 B. O. Okesola, V. M. P. Vieira, D. J. Cornwell, N. K. Whitelaw and D. K. Smith, Soft Matter, 2015, 11, 4768.

29 S. R. Jadhav, P. K. Vemula, R. Kumar, S. R. Raghavan and G. John, Angew. Chem., Int. Ed., 2010, 49, 7695.

30 A. Vidyasagar, K. Handore and K. M. Sureshan, Angew. Chem., Int. Ed., 2011, 50, 8021.

31 A. Prathap and K. M. Sureshan, Chem. Commun., 2012, 48, 5250.

32 J. Gao, K. Feng, H. Li, Y. Jiang and L. Zhou, RSC Adv., 2015, 5, 68601.

33 M. Samateh, A. Vidyasagar, S. R. Jadhava and G. John, RSC Adv., 2016, 6, 107598.

34 N. Mohmeyer, P. Wang, H.-W. Schmidt, S. M. Zakeeruddin and M. Grätzel, J. Mater. Chem., 2004, 14, 1905.

35 W. Chen, Y. Yang, C. H. Lee and A. Q. Shen, Langmuir, 2008, 24, 10432.

36 S. Grassi, E. Carretti, L. Dei, C. W. Branham, B. Kahr and R. G. Weiss, New J. Chem., 2011, 35, 445.
37 C. Tong, K. Fan, L. Niu, J. Li, X. Guan, N. Tao, H. Shen and J. Song, Soft Matter, 2014, 10, 767.

38 S. Mukherjee, C. Shang, X. Chen, X. Chang, K. Liu, C. Yu and Y. Fang, Chem. Commun., 2014, 50, 13940.

39 (a) A. M. Vibhute, V. Muvvala and K. M. Sureshan, Angew. Chem., Int. Ed., 2016, 55, 7782; (b) A. Prathap, K. M. Sureshan, Angew. Chem., Int. Ed., DOI: 10.1002/ anie. 201704699.

40 S. Roy, A. Chakraborty and R. Ghosh, Carbohydr. Res., 2008, 343, 2523.

41 O. Gronwald and S. Shinkai, Chem.-Eur. J., 2001, 7, 4328.

42 S. Mukherjee and B. Mukhopadhyay, RSC Adv., 2012, 2, 2270.

43 Rajkamal, D. Chatterjee, A. Paul, S. Banerjee and S. Yadav, Chem. Commun., 2014, 50, 12131.

44 Rajkamal, N. P. Pathak, D. Chatterjee, A. Paul and S. Yadav, $R S C A d v ., 2016,6,92225$.

45 S. S. Babu, V. K. Praveen and A. Ajayaghosh, Chem. Rev., 2014, 114, 1973.

46 L. S. Birchall, S. Roy, V. Jayawarna, M. Hughes, E. Irvine, G. T. Okorogheye, N. Saudi, E. D. Santis, T. Tuttle, A. A. Edwards and R. V. Ulijn, Chem. Sci., 2011, 2, 1349. 